\title{
Design and Implementation a Student's Transcript System
}

\author{
Sabah A. Abdulkareem, Yousif N. Hatif \\ Department of Computer Engineering, College of Engineering, University of Diyala \\ sabahanwer55@gmail.com
}

\begin{abstract}
The importance of information at present has increased the importance of database systems to organize the information we need, and to provide it for use in the appropriate and timely manner. Thus, the science of managing database systems evolved from a subtopic in computer applications to a basic subject and a major component of modern computer science, thus, database systems have become a key part of the Platform for Computer Science.
\end{abstract}

This paper presents the design and Implementation of a Transcript System for college of engineering, University of Diyala, this system releases transcript by retrieving student's data from database which later stored in Microsoft access database with user interfaces designed by using the tools of Microsoft Visual Studio 2010 (.Net). This system solves most of the problems which happen by using manual methods such as delay in the delivery student's transcript, mistakes in the student data in the transcript (name, average...).

The system provides sufficient capacity to facilitate the work of the registration staff with respect to data entry and validation and increases efficient service delivery and benefits both registration staff and students.

Keyword: Database Management System; User Interface; University of Diyala, Registration Department.

Paper History: Received: 12/12/2017, Accepted:

$20 / 2 / 2018$

\section{Introduction}

Since 1960, most businesses started, to store and save data on the computers, especially in developed countries, the computing experts developed theories and methods to re-use of data that are saved in the computer, and this data is called computerized. Which reflect using these files and the methods used to deal with these files. Huge files can store as a base that contains all of data as records and tables. Which can be used at a later, this base is called a database [1] [2]. Because of the importance of the database and its impact in many areas and main activities, a system must be adopted to organize and manage the stored information, this system is called Database Management System, which is a set of programs that can enable us to enter, regulate and choose data in database (DBMS) [2] [3].

Sometimes, projects of Information systems are started to improve the accuracy of processing data. The database will remain consistent and accurate because it is stored in the computer thus resulting is a good performance. Student Database Information System needs to store a huge amount of data so it was needful to evolve software, which can restore data quick.

\section{Problem Statement}

In the past, when the student needs a transcript[4] he/she submits a request to the registration department this request which contains many fields that must be dictated by the student such as the name, first or second attempt, graduate year,.. As a result of this request, the registration staff manually extracts the student file from the records and finds all required fields in the document. So registration staff manually writes and print this transcript based on student information as shown in Figure 1. Thus this system is so weak to meet specific requirement because the staff may mistake in student name or his average or another field [5]. 


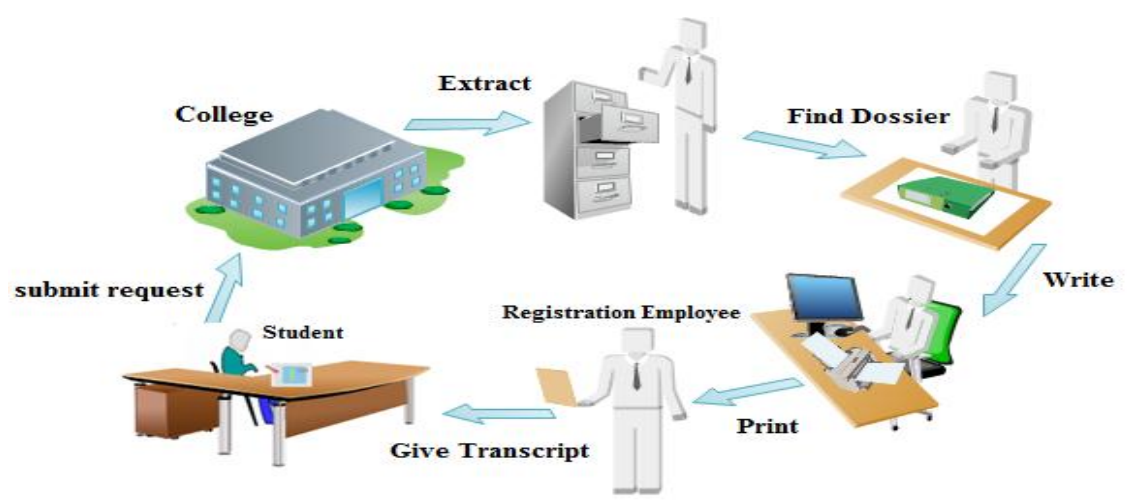

Figure 1: Current Mechanisms for Student Transcript release

\section{The Purpose of the Study}

The main purpose from this work is build system based on database to build student information management system Especially for the graduation document in the registration department - college of engineering, this system will solve most of the problems which are happen by retrieving student information from manual archives.

\section{Methodology}

The methodology is very significant to assure that the new system would give benefits to the college. Before starting the process of collecting data for the purpose of analysis and using it in the design of an information system based on the computer, it must first define the goals for which this system was required, also define the desired requirements in the system design. therefore there is a good analysis outcomes in successful design which meets with the beneficiary body requirements. This section provides a summarized description of the methodology applied to develop the proposed system. The methodology involves system description and system analysis.

\section{Proposed system}

The proposed system shown in Figure 2. replaces the existing system, which is old files system by Dossiers. A student's Transcript system is more accurate and useful than the current system, it reduces the time, participant in the processing and retrieval of information. It has the ability to store, remove, and update processing data entered into it.Students' transcript is the abstract of each of the fouryear performance in college of engineering university of Diyala for all departments in the college, it involves the concerned party, student's name, his(her) nationality, department, attempt(first or second),average of four academic years, type of study (morning or evening) and year of graduation.

A transcript is also required by a student who has finished study of B.Sc. and who desired to introduce to study the highest education or who desired to secure a job.

The Students' transcript is an integrated system, which provide eases of access to database and write reports and makes decision. It is simple in its structure, processes, steps should comprehend maintained easily, and it is more flexible to deal with new requirements in the future (Figure 3. showed relationship between tables). It has the ability to expand and update database, so that the new requirement can be easily appended without needed to design the new system. In addition to the format in the transcript should be the same in all things font face, font, bold, font color, indent and many of the properties, thus improving work efficiency.

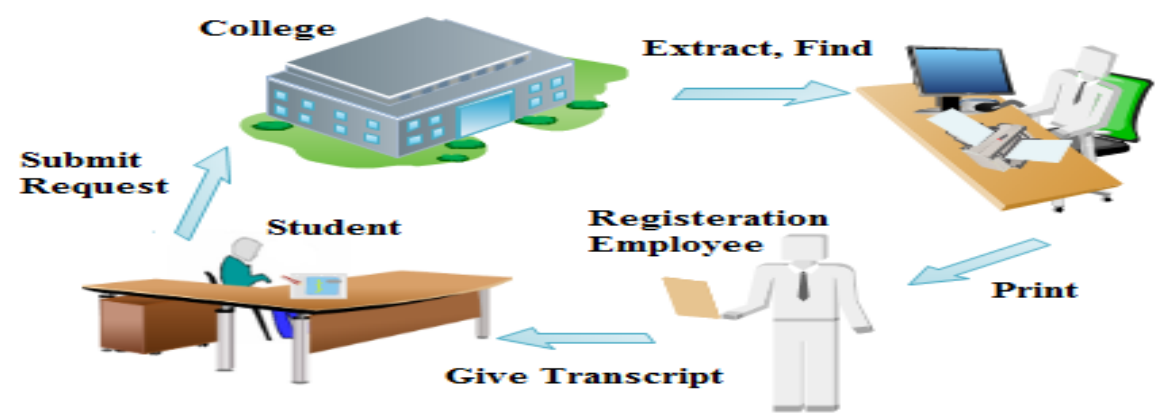

Figure 2: proposed System 


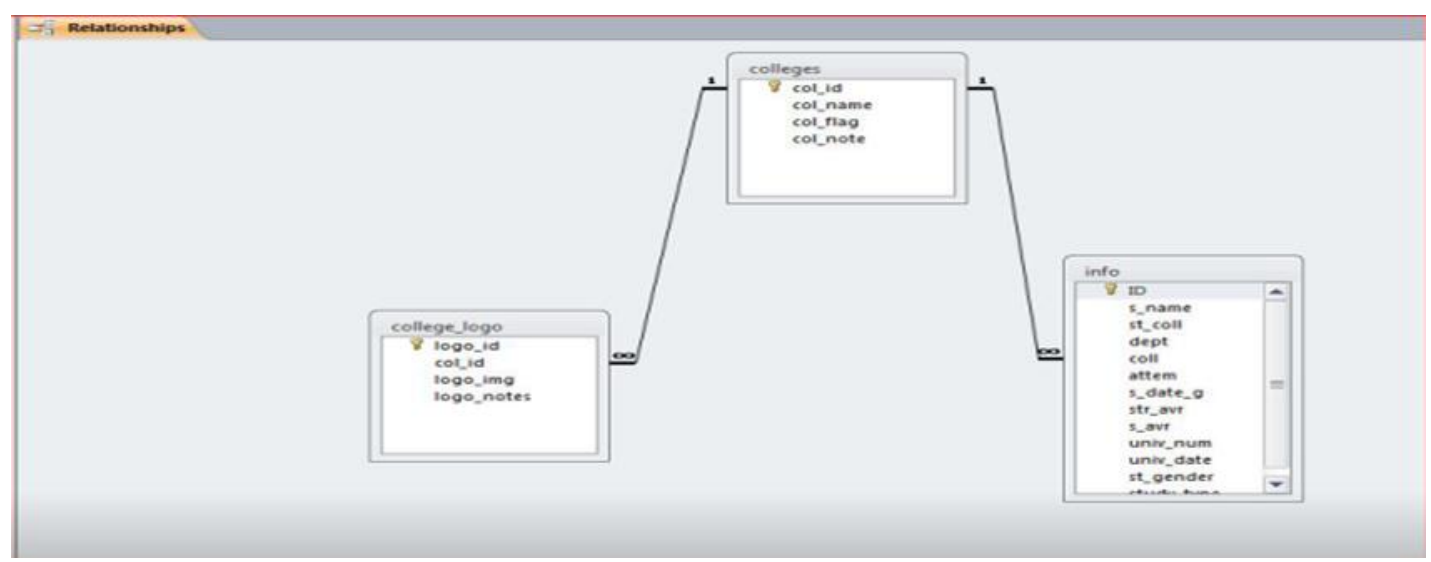

Figure 3: Tables’ Relationship

\section{Implementation and Result}

It was the visual studio is used as the Integrated Development Environment (IDE) to implement the system. visual basic.net programming language is used to create the user interface that permit to interact delightedly with the system. Microsoft access 2010 is connecting to database by Open Database Connectivity (ODBC) techniques. Comprehensive testing was done to guarantee that the system procedures are done the fullest. The result is very good and reduces the time to several minutes instead of one day or two days.
The Graphical User Interface (GUI) for recording student information by the system administrator and to change dean's name, document's organizer, and director, is shown in Figure 4.The administrator of system is an employee of the registration department in the college.

Evaluation was completely done to assure that the system meet the needed specifications and requirements. The system was monitored and found that it works in an integrated manner and without delaying in the time.

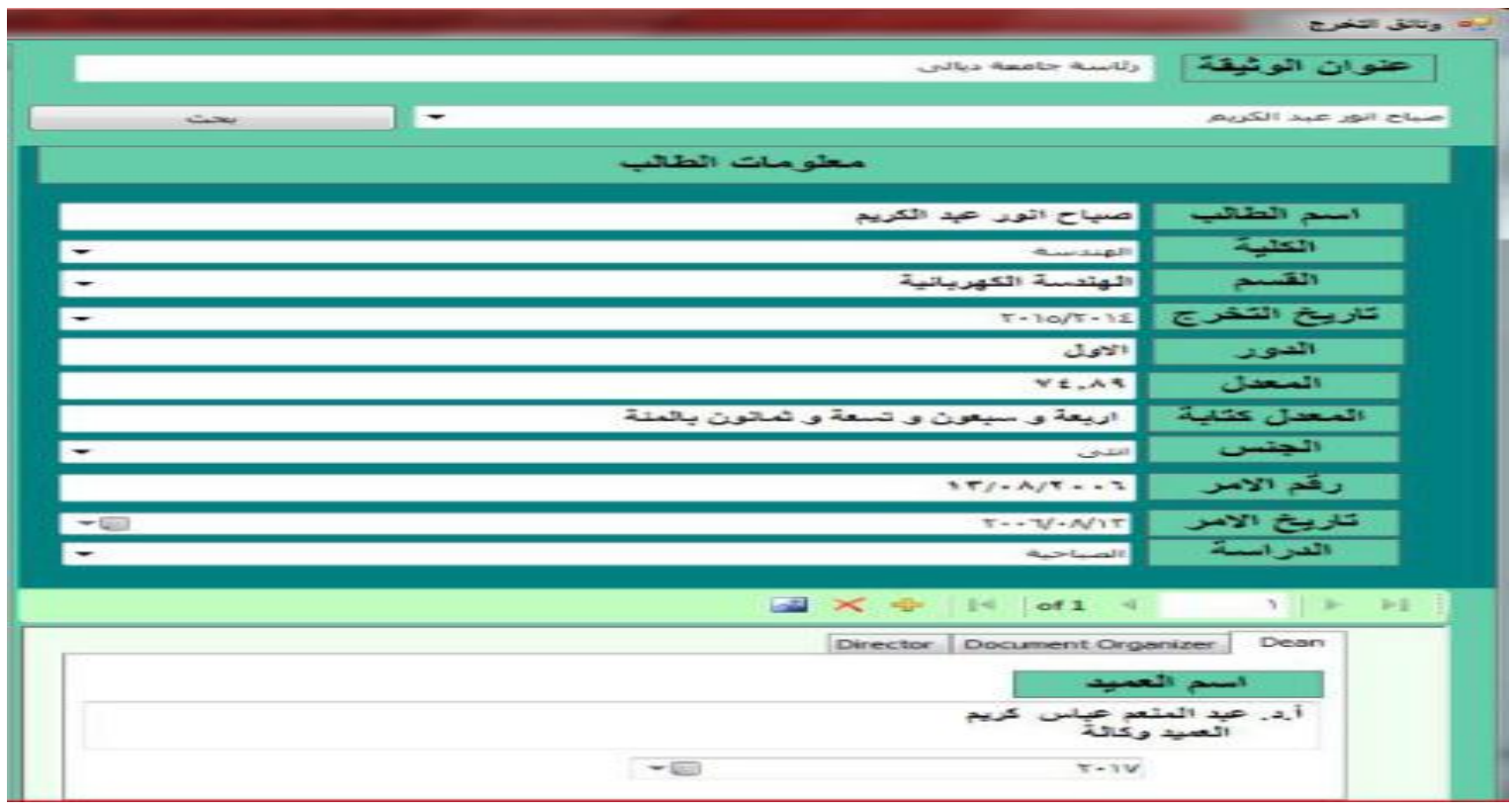

Figure 4: Graphical User Interface (GUI) 
The Implementation contains all the activities that happen to convert the current system to the new system; the suitable implementation is wanted to give a dependable system to meet the proposed system was running with the current system in parallel for checking the new system. This provides safety, and detects errors if there is a flaw in the transcript system. Figure 5. and Figure 6. are showen the implementation of the system.

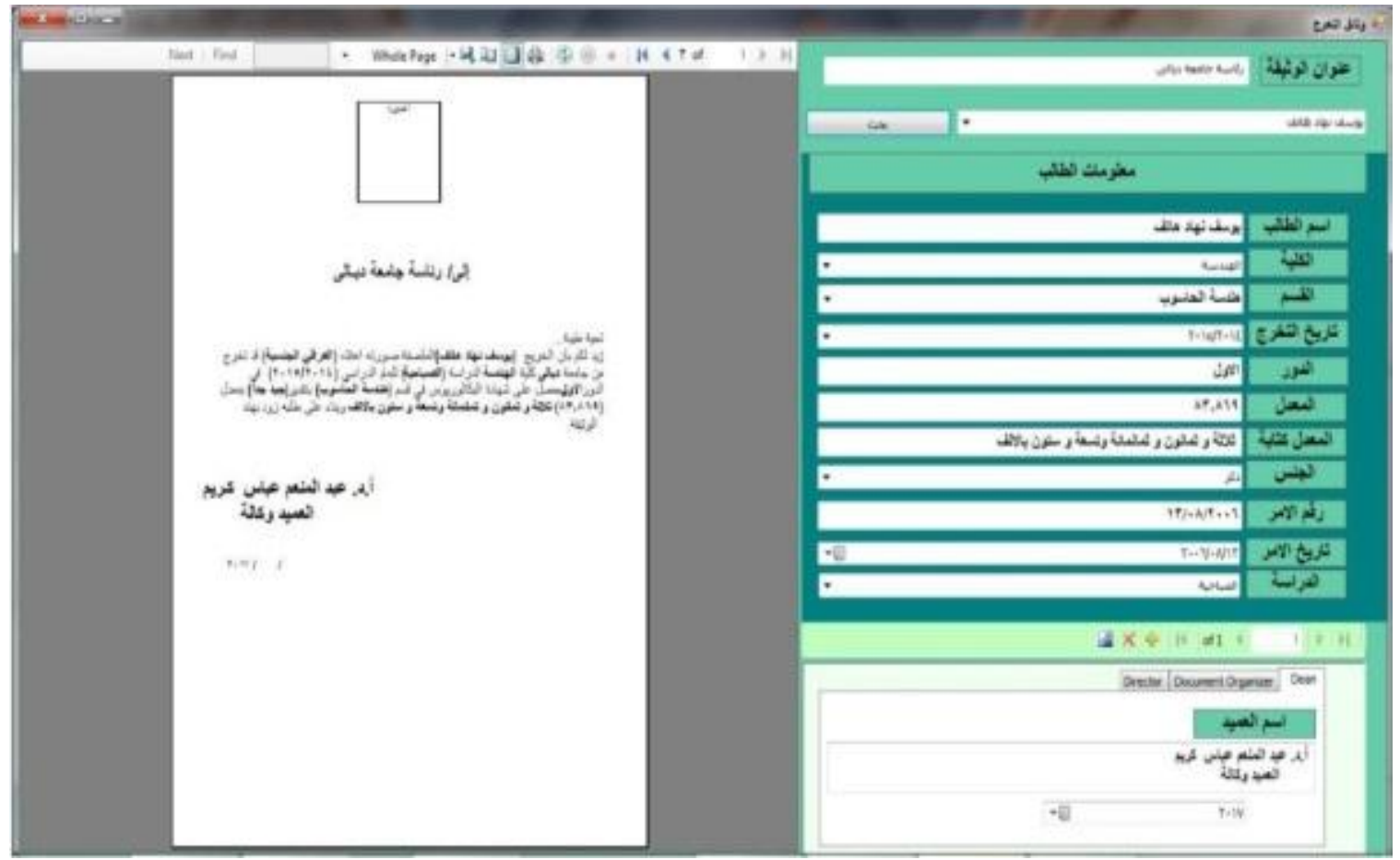

Figure 5: the front face for the transcript

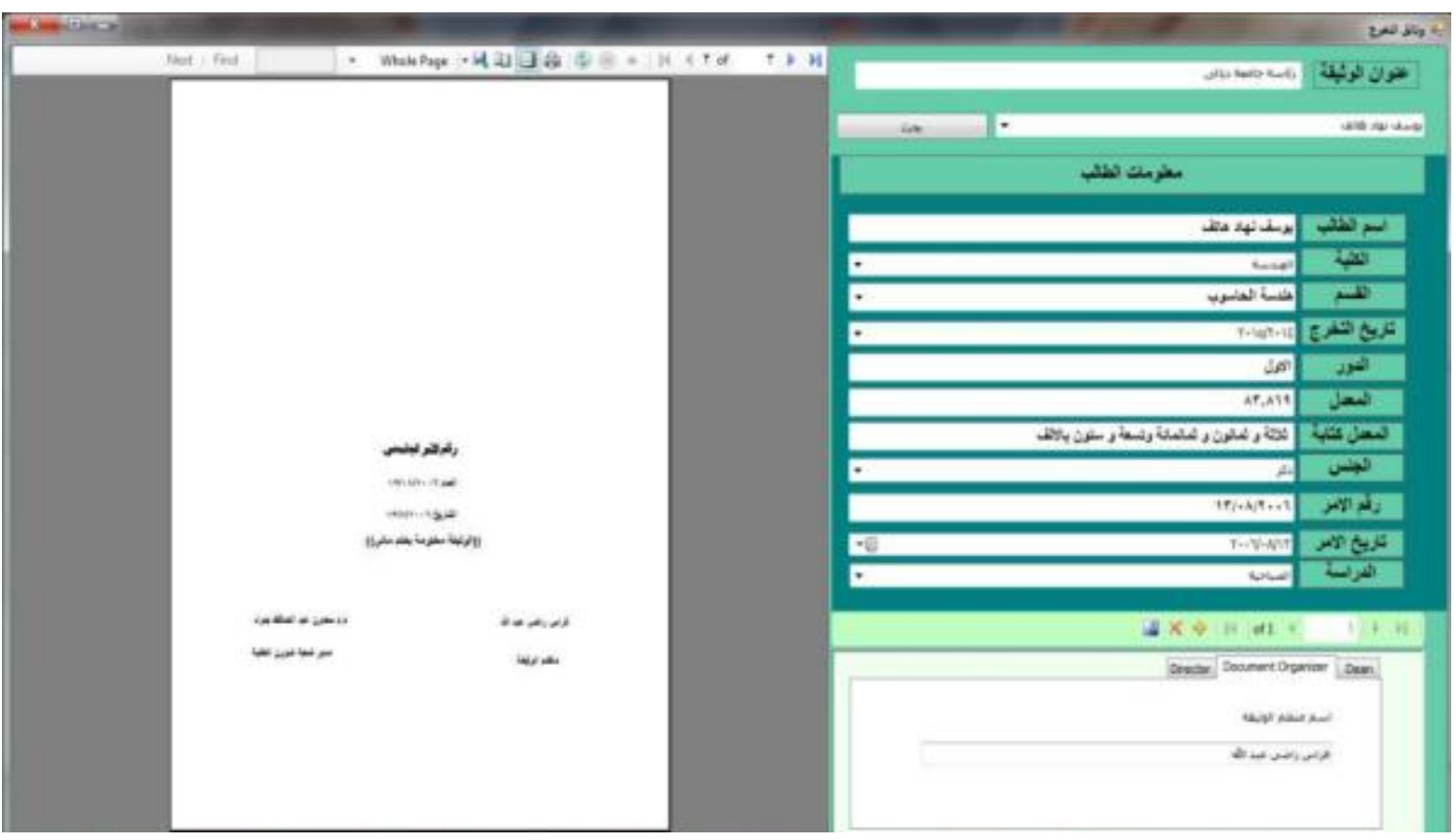

Figure 6: the background of the transcript 
It can release the transcript as PDF file and manipulate it later by using any PDF driver for example (Viewing, Printing...), as example shown in Figure 7 and Figure 8.

We can release the transcript as Microsoft Word file and manipulate it later by using any Microsoft Word for example(Viewing, Printing, updating, deleting...).

It can release the transcript as Microsoft Excel file and manipulate it later by using any Microsoft Excel for example(Viewing, Printing, updating, deleting...).

\section{Conclusion and Future Work}

The main aim to design and implement this system is to gather student's data in one place and make different transactions, modify, update on it and retrieve this data depend on the need of creating the report for transcript. This goal has been achieved, as well as the tasks for which this system was designed. This system transfers the manual work in Registration department in College of Engineering -University of Diyala to the existing computer. It also enables the registration staff to get data through an easy to use interface. This system can enhance college management to perform its tasks efficiently This system will reduce effort required and time in the process of management information, organize the administrative and academic affairs of each student, also this system needs one employee, instead of a large number of staff to do the tasks. The system provides the ability to perform data entry and update operations by specific employees in the registration department. The employee is authorized to conduct basic data (such as searching, presentation, updating and deletion) by authorizing the system to be used.

It must encourage the students who are wanted in building database system, supported them, and encouraged them to work in a team for developing software applications. so this paper could be useful for any user who wants to make a project on similar subject. it gives the system greater potential by making choices for colleges and departments and transfer this system to all college in Diyala University in order to the unification the student transcript in this University.

It transfers this system from local form to student transcript system using Web services

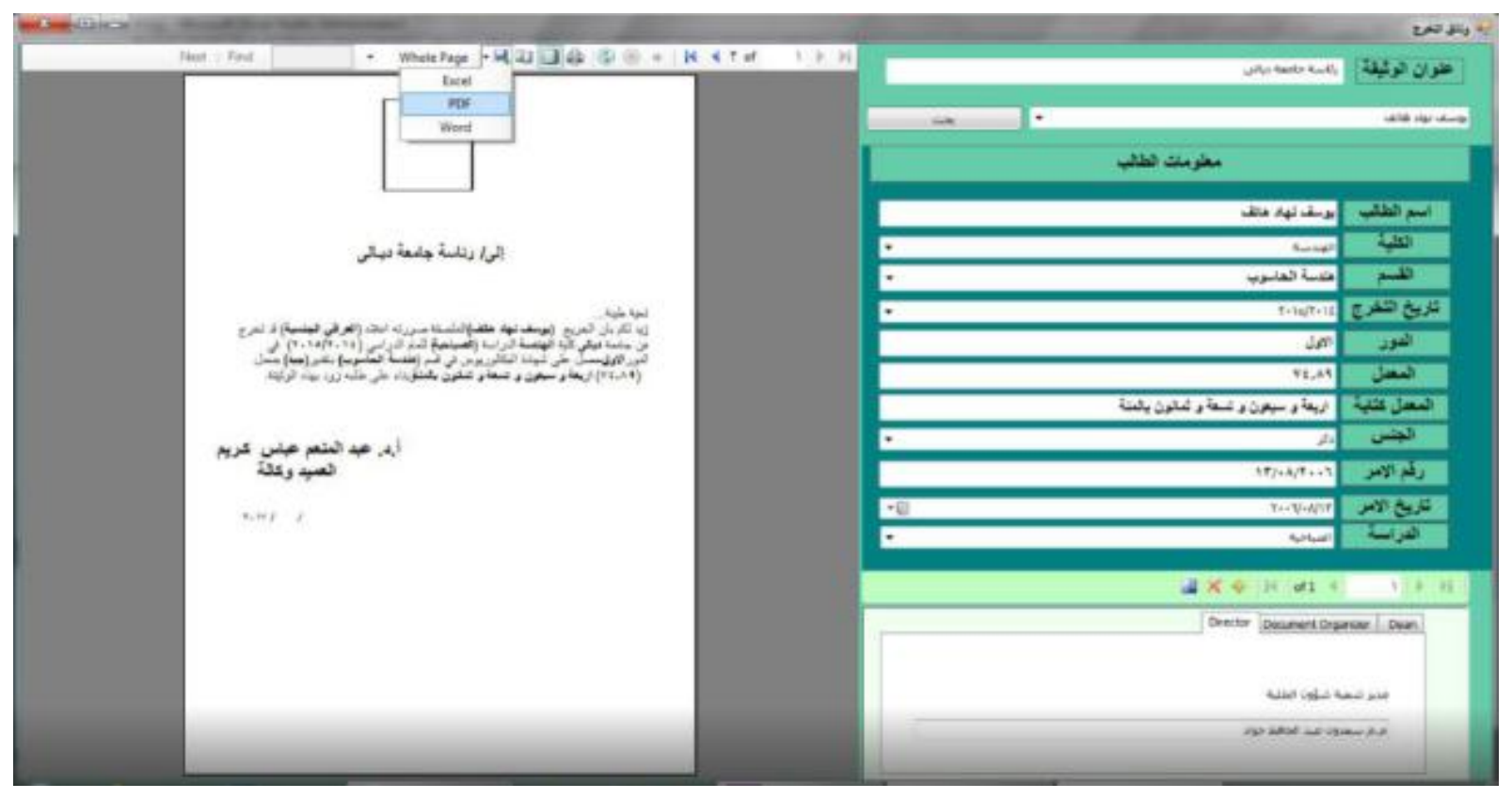

Figure 7: Release transcripts as Excel, PDF, and Word 


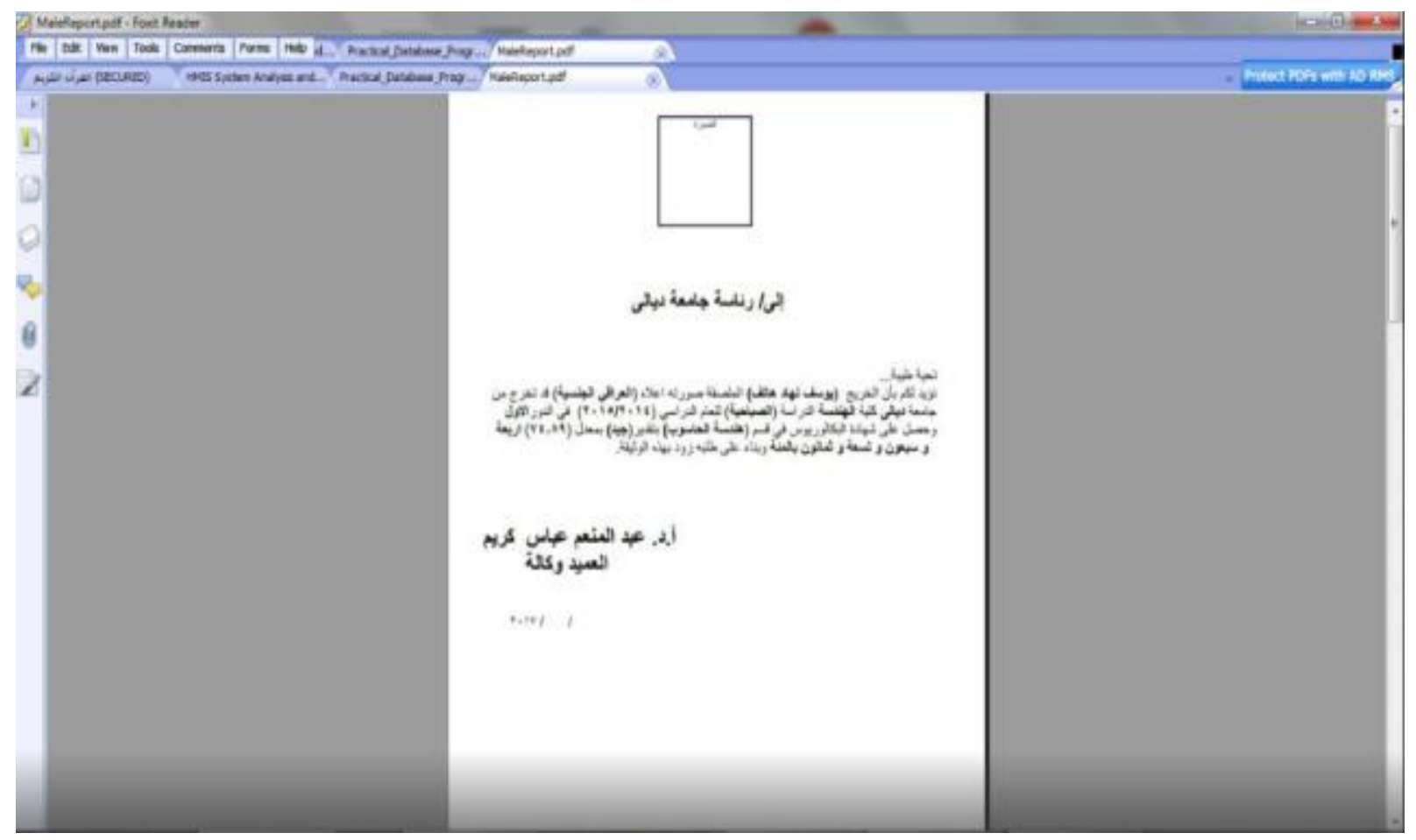

Figure 8: Release transcripts as PDF

\section{References:}

[1] Ahmad, Noraziah, et al. "A Novel Database Design for Student Information System 1." (2010).

[2] Bai, Ying. Practical database programming with Visual Basic. NET. John Wiley \& Sons, 2012.

[3] Almehmes, Ihsan Ali Hassan, Design and implement of database student information management system in College of Medicine, University of Diyala, Diss, 2014.

[4] https://www.pearsonhighered.com/assets/samplechapter/ 0/6/7/2/0672323435.pdf

[5] DESIGN AND IMPLEMENTATION OF STUDENT'S TRANSCRIPT GENERATING SOFTWARE Https://Www.Grossarchive.Com/Upload/1416987395.H tm

[6] Garikipati, Ramani, and Billy BL Lim, Design and implementation of an e-Transcript system using Web services, Computing \& Informatics, 2006, ICOCI'06, International Conference on IEEE, 2006. 